\title{
PERSPECTIVES ON THE FACTORS INFLUENCING STUDENT SOCIAL WORKERS IN THE EXECUTION OF THEIR RESEARCH PROJECTS AT FOURTH LEVEL IN AN OPEN DISTANCE-LEARNING CONTEXT
}

\author{
Mankwane Makofane
}

\section{INTRODUCTION AND BACKGROUND}

The inability of the fourth-level student social workers to complete their research projects on time has a negative impact on the throughput of the Department of Social Work at UNISA and hampers the implementation of the recruitment and retention strategy of social workers initiated by the National Department of Social Development. With reference to the latter, Mr Mnguni, a policy developer in the Service Standards Directorate of the National Department of Social Development states that "The Recruitment and Retention Strategy for Social Workers has been adopted and implemented since 2004 by the Department of Social Development; it is now part of the bigger Human Resource Strategy in the department. The implementation of the following programmes bears reference to the implementation of the strategy: the regrading of social workers' salaries in 2004, the Occupational Specific Dispensation (OSD) in 2010, the scholarship programme, career fairs and now the exchange programme with the United Kingdom. The department is now preparing for evaluation of the strategy."

The Department of Social Work at UNISA currently trains $70 \%$ of all the social workers in South Africa (Department of Social Work, 2008:5). In 2010 the Department had a total of 27924 students registered in all 24 modules that are offered (UNISA, 2010c). Narrowing the discussion to the number of students who were enrolled for the research module at fourth level (SCK410B) in 2010, Table 1 below provides a statistical analysis to show the number of students who registered and their general performance. Of the 112 students who did not complete the module, 8 deregistered, 35 did not submit the final research report (Assignment 3) and 69 failed.

TABLE 1

AN ANALYSIS OF THE 2010 REGISTRATION AND PERFORMANCE OF STUDENTS IN MODULE SCK 410

\begin{tabular}{|c|l|}
\hline Number of students & \multicolumn{1}{|c|}{ Status } \\
\hline 361 & Students registered in 2010 \\
\hline 353 & $\begin{array}{l}\text { Students admitted for examination (submission of Assignment 3 - } \\
\text { Research report) }\end{array}$ \\
\hline 318 & Handed in Assignment 3 for assessment \\
\hline 249 & Passed \\
\hline 69 & Failed \\
\hline
\end{tabular}

UNISA Examination: Mark Composition Report for SCK 410B (2010/12/02)

Research is an essential component in social work education. Among the numerous challenges in social work education, a persistent one for both educators and students is teaching and learning research (Hardcastle \& Bisman, 2003:31). A survey conducted by Strydom (2008:386) revealed unsettling findings indicating that some lecturers who were responsible for teaching the research module(s) were not always committed to research themselves; some were not up to standard regarding research and were not always interested in research, yet they were expected 
to motivate students for the research module; they devoted time to heavy teaching loads and research was regarded as an additional challenge. Other studies (Dunlap, 1993:300; Strydom, 1998:65) also show that educators often transmit negative attitudes towards research. Conversely, the ongoing tensions within the profession about the nature and function of research are perceived as partly responsible for these difficulties (Hardcastle \& Bisman, 2003:31).

Engaging students in research education is a challenging effort (Cameron \& Este, 2008:390), regardless of the location of the institution. For instance, the students in the study by Lundahl (2008:274) explained their lack of interest in research by stating that "such courses are boring or irrelevant to social work activities." Additionally, Cameron and Este (2008:391) presented a comprehensive literature review on the fact that a significant number of social work students enter research classes with a negative attitude towards research. Comforting, though, is the conclusion reached by Unrau and Grinnell (Jr) (2005:640) that "a growing body of literature gives support to the notion that research courses have a positive impact on students' attitudes and knowledge of research concepts and skills." This calls for increased educator awareness of students' levels of anxiety, the validation thereof and the engagement of students in building confidence and an appreciation of research.

The current study is partly a response to Strydom's (2008:392) recommendation that the viewpoints of students regarding research should be explored as a follow-up to his investigation, which focused mainly on the viewpoints of social work lecturers on the importance of the research module(s); students' views on the importance of the research module(s) as envisaged by the lecturers; credits allocated to the module(s); the duration of teaching and the level of study of the research module(s).

Social work educators are expected to teach future social workers to value research and aspire to become researchers-practitioners and promote evidence-based practice (EBP). The ODL institutions similar to on-campus institutions have challenges and responsibilities to teach, supervise $^{1}$ and offer adequate support to fourth-year social work students who have enrolled for the research module. Effective support for these students requires effective interaction between students and supervisors - a process viewed by Todd, Smith and Bannister (2006:166) as an overarching function of supervisors to facilitate the students' "journey" in the completion of their research projects. However, it should be borne in mind that in the ODL context, face-face contact with students is minimal compared with the situation at on-campus institutions.

At UNISA fourth-year student social workers who meet the set criteria are permitted to register for a maximum of ten modules ${ }^{2}$ (each with an equivalent number of credits) in one year (UNISA, 2010a:139-140). Therefore, the onus lies on students to make realistic decisions on

\footnotetext{
${ }^{1}$ Supervision of students is not provided at regular intervals on a face-to-face basis as at residential universities (because of the geographical distances involved), but the principal lecturer uses different multimedia platforms (as indicated in Table 2) to provide supervision. Furthermore, the markers, in their comprehensive feedback, provide guidance and supervision.

${ }^{2}$ SCK 401A Social Casework: working with individuals - integrated theory and practice; SCK 402B Social Casework - working with couples and families - integrated theory and practice; SCK 403C Social group work with children and youth - integrated theory and practice; SCK 404D Social group work with adults - integrated theory and practice; SCK 405E community work: planning and integrated practice; SCK 406F Community work: execution of a project; SCK 407G Social work management: the social work organization - integrated theory and practice; SCK $408 \mathrm{H}$ Social work management: the social worker as employee and manager; SCK 410B Research project - planning and execution; SCK 411C Statutory work, ethics and supervision.
} 
the number of modules that they will be able to manage. Most student social workers are in full-time or part-time employment, and/or have families to look after and thus the number of modules for which they qualify to register may pose a challenge regarding time management and the ability to comprehend all the material at their disposal.

In addition, students have different learning styles and approach learning through various methods. It is assumed that these modes of learning may account for the disconnect between the learning of research methods and their application. Unrau and Grinnell (Jr) (2005:641) assert that the literature informing educators on how students learn research is diverse and somewhat fragmented. This assertion poses a challenge for the UNISA social work educators, as they are providing education to students from diverse backgrounds.

The aim of this paper is to present the perspectives of the 2010 students, the principal lecturer ${ }^{3}$ and markers ${ }^{4}$ on factors influencing the students' planning, execution and completion of their research projects. Proposed here are suggestions for the Department of Social Work at UNISA and recommendations for future research.

\section{CONCEPTUALISATION}

For the purpose of this study, important terms will be explained below.

\section{Open learning}

The University of South Africa (UNISA) dominates distance education in South Africa. It is regarded in the tertiary landscape of South Africa as the most affordable university, with the result that it attracts large numbers of students who have recently completed school (Kilfoil cited by Schenk, 2009:299). UNISA (2008:2) provides a comprehensive view of open learning as "a multi-dimensional concept aimed at bridging the time, geographical, economic, social, educational, and communication distance between student and institution, students and academics, students and courseware, and students and peers".

Bourn and Bootle (2005:344) define open learning as "education and training that aims to meet the needs and requirements of individual students and can help to facilitate access to learning for the disadvantaged group". Furthermore, open learning is characterised as being learnercentred, because individuals can take responsibility for their own learning and study at their own convenience (Bourn \& Bootle, 2005:345).

Distance learning

According to Siegal, Jennings, Conklin and Napoletano-Flynn (1998:72), distance learning is a sub-set of open learning, meaning that it is "a formal manner of teaching or instruction where the teacher and learner are in separate locations most of the time but are linked by a communication medium"; this is the case at UNISA. Even though many sceptics may express

\footnotetext{
3 The principal lecturer of this module also fulfils the primary planning, coordination, lecturing and administrative functions relating to the module. In view of this, the concepts "principal lecturer" and "coordinator" will be used interchangeably in referring to this person.

${ }^{4}$ The markers used to assist with marking of the assignments related to Module SCK 410B should be working towards obtaining a master's qualification in Social Work or should have completed postgraduate studies. They should complete the orientation course on the use of assessment templates to facilitate the assessment of assignments and modes of providing feedback to students. (Besides the lecturing staff members in the Department who mark research assignments, external social workers meeting the stated requirements are also employed as markers.)
} 
doubts about the interaction between students and educators in distance learning, Roblyer and Ekhaml (2000:1) have cited studies which concluded that "with proper instructional design, distance courses actually can be more interactive than traditional ones, providing more personal and timely feedback to meet students' needs than is possible in large face-to-face courses".

Open distance learning (ODL)

Open distance learning gives students increased autonomy as well as choice and control, including components of flexibility (students choose what, where, when and how they learn) in the learning process (Lewis, 1995:33). However, the students have a responsibility to exercise self-discipline and not be swayed in different directions by the whims of others, such as family and friends. The affective aspect, which to a large extent concerns the feeling of power and independence in the learning situation, may be keenly felt in distance education, where students are more in charge of the learning process (Blakely,1992:215). Open distance learning focuses on removing learning barriers, being student-centred, supporting students, facilitating and developing flexible learning programmes (UNISA, 2008:2).

In summary, open distance learning refers to a situation where an institution offers students from diverse backgrounds an opportunity to register for modules or courses, and to take responsibility and become actively involved in their own learning process towards the acquisition of a degree or a certificate. ODL is learner-centred and the students' learning takes place at their own convenience. Different modes of instruction and communication are utilised for students to remain in contact with educators. Modern technology has made this process easy and less cumbersome (i.e. seminars and video conferences are used by lecturers for face-to-face contact with students).

\section{MODULE DESCRIPTION}

Clearly, there are many challenges on how to deliver research content to social work students. Hence, approaches adopted by research educators vary greatly. They may be influenced by the context and/or the approach that the school or department of social work has adopted. For instance, the Department of Social Work at UNISA follows a person-centred approach (PCA), which according to Schenk and Grobler (2009:4) aims at enabling people (individuals, families, groups and communities) "to discover for themselves what they are struggling with and then find their own unique way forward". Because of the fit between PCA and the qualitative approach, the students do the planning, execution and documentation of their research projects (Module SCK 410B) based on the qualitative research approach. The qualitative approach focuses on the study of people in their natural environment as they go about their daily lives (Emerson cited in Tutty, Rothery \& Grinnell, 1996:4).

Thus, the purpose of the research module, according to Alpaslan (2010:2), is to provide students with a step-by-step guideline on how to plan a research project using a qualitative approach; implement the plan; and record the research process and the research findings in a research report within the person-centred approach.

Consistent with several research reports that discuss the use of active learning strategies in teaching research methodology to social work students (Lundahl, 2008:276), Alpaslan (2010) designed activities that students should perform to enable them to complete specific assignments that culminate in the final research report.

The outcomes of the module SCK 410B (Social Work Research: A step-to-step guide on how to conduct $4^{\text {th }}$-year research project and write the research report) and the assessment criteria 
are succinctly presented in the study guide for the module. The outcomes of the module are as follows:

- Students will be competent in demonstrating the ability to draw up a research plan for a research project focusing on a selected research topic in social work;

- Students will be competent in demonstrating their ability to implement the research project;

- Students will be competent in demonstrating their ability to produce a research report (Alpaslan, 2010:2-3).

Two (one per semester) compulsory research seminars were scheduled for 2010. Prior to the attendance of the research seminars, students are expected to have familiarised themselves with information relating to the module (SCK 410B) as specified in the tutorial letter. The students are orientated in a face-to-face workshop at the beginning of the academic year with a view to explaining the purpose of the module and to orientating them specifically towards Assignment 1 - Drafting the Research Plan Grid. The Grid is a "road map" for their proposed research project in terms of Tutorial Letter 101 and 501 of 2010. The grid counts $10 \%$ towards the final mark. The expectations regarding the two additional assignments and their activities are also addressed.

Students receive detailed typed feedback on Assignment 1 and they need to incorporate the feedback, adjustments and suggestions made by markers into Assignments 2 and 3. On receipt of Assignment 1 students can then commence with Activity 2, namely; procuring a sample, conducting fieldwork (i.e. collecting qualitative data by means of semi-structured interviews and analysing the data) and starting with the compilation of the draft research report (Assignment 2).

A second workshop is conducted during the first week of July. In Johannesburg and Pretoria faceto-face contact workshops were conducted, while video conferences were used for the other venues such as Cape Town, Bloemfontein, Kimberley, Port Elizabeth, Durban and Polokwane. At the workshops the focus is mainly on how to analyse qualitative data using Tesch's approach (cited in Creswell, 2009) and the compilation of the draft research report. Clearly, students who have had face-to-face contact with facilitators benefit more from the workshop compared with those who attended the video conferences (especially in the bigger regions such as Durban and Polokwane). Students receive detailed handwritten and typed feedback on Assignment 2 and are expected to incorporate the feedback, adjustments and suggestions into Assignment 3, their final research report which counts $90 \%$ towards the final mark.

Since direct face-to-face supervision is not provided at regular intervals, as is the case with students studying at residential universities, because of the geographical distances involved, the principal lecturer uses different multimedia platforms (i.e. telephone discussions, e-mails, inscriptions on discussion form in myUnisa) to provide supervision. Furthermore, the markers provide guidance and supervision in their comprehensive feedback.

The markers used for marking assignments related to Module SCK 410B (Social Work Research) should be working towards obtaining a master's qualification in Social Work or should have completed postgraduate studies. The markers should complete the orientation programme, which covers the use of assessment templates to facilitate the assessment of assignments and modes of providing feedback to students.

The principal lecturer for the module is a professor who assumes multiple roles and functions, such as the compilation of study guides and tutorial letters for students; coordination of 
students' and markers' activities; and administration and quality control (quality assurance). A summary of the principal lecturer's roles and functions is presented in Table 2 below.

TABLE 2

MULTIPLE ROLES AND RESPONSIBILITIES OF THE PRINCIPAL LECTURER

Functions of the principal lecturer Students

Compile a study guide and tutorial letters for students informing students about scheduled workshops and deadline for submission of Assignment 1-3. Communication with students

Use technology (e.g. emails through myUnisa, telephones, sending short messages to cell phones) to be in constant contact with student.
Secure venues for workshops in different UNISA training centres across the country.

Facilitator - facilitate research workshops in different training centres and involve markers to assist with cofacilitation of workshops especially in the bigger centres (i.e. Johannesburg and Durban).

Schedule and conduct video conferences.

Allocation of students

Ensure that each student is allocated a marker.

Fill in for markers by attending/handling students' telephonic queries.

Attend to students' queries at the end of the year. Coordinate the work of students who obtained a supplementary examination.
Functions of the principal lecturer - Markers

For uniformity and consistency, the principal lecturer in collaboration with the markers designs templates for markers to use when marking Assignment 1 (The Research Plan Grid).

Designs and compiles markers' code list to enable markers to give students extensive and structured feedback highlighting what they have done well and where they fell short, including the improvements they need to make.

The principal lecturer fulfils an administrative role by executing the following activities:

Distribute Assignments among markers.

Enter students' marks for Assignment 1 and 3.

Forward Research Reports to the external examiner for moderation.

Compute and enter students' final marks.

Trainer - provide training for markers on how to facilitate research workshops.

Some of the markers have observed how these workshops are facilitated and subsequently cofacilitated, some with the principal lecturer.

On an annual basis, the principal lecturer (with inputs from markers and lecturers within the Department) reviews and updates all documents used in this module such as tutorial letters, 
study guide and templates to ensure that the suggestions by markers and/or students are incorporated.

\section{RESEARCH QUESTION AND AIM}

Qualitative studies ask research questions and avoid making predictions or putting forward a hypothesis (Creswell, 2009:129). Therefore, a qualitative research question will not be hypothetical, proving or disproving a certain truth, but would rather explore a phenomenon to obtain a "depth of understanding" (Fossey, Harvey, McDermott \& Davidson, 2002:723). Hence, the following question was posed to provide direction for this study: What are the perspectives of the 2010 students, the principal lecturer and markers on factors influencing student social workers in the planning, execution and completion of their research projects at $4^{\text {th }}$ year level in an ODL context? The aim of the study was: To discover factors that influence the fourth-year student social workers' planning, execution and completion of their research projects in an ODL context.

\section{RESEARCH METHODOLOGY}

A qualitative research approach was employed, since it helps researchers to understand social life and the meaning that people attach to everyday life (Delport \& Fouché, 2005:261). It also encourages a richer understanding of people's subjective experiences, behaviour and knowledge (Monette, Sullivan \& DeJong, 2008:224) and may foster anti-oppressive practice (O'Connor \& O'Neill, 2004:23). A qualitative, descriptive and contextual design was utilised, since the study intended to explore and describe the participants' perspectives on factors that influence the implementation of research by the fourth-year student social workers within the ODL context (Fossey et al., 2002:717). Two non-probability sampling techniques, namely; convenience and snowball were employed to procure a sample of two interested groups: (1) students who had completed Module SCK 410B in 2010, and (2) the principal lecturer for the modules and the markers. The researcher emailed the information about the proposed research project to four students from the class of 2010, whose addresses were obtained from the department, and they in turn forwarded e-mail addresses of their former classmates whom they thought would be willing to take part in the study.

Two guides (Guide A for students and Guide B for the principal lecturer and markers) with open-ended questions were designed to obtain the views of the participants on aspects that influence the students' completion of their research projects. Twenty-three guides with openended questions were e-mailed to students who had successfully completed Module SCK 410B (Social Work Research) in 2010. Of these students, only eight responded. This response rate is attributed to the fact that the conditions of most students may have changed. However, when analysing the responses provided by the participants, the author concluded that data saturation had been reached, since no new information emerged from the responses provided by the eighth participant. Telephonic discussions were conducted with some participants to seek clarification on some of their responses. Guide B with open-ended questions was e-mailed to the principal lecturer and six markers who were involved in guiding students with research projects in 2010. The principal lecturer and five markers responded. Two face-to-face semistructured interviews were conducted with the principal lecturer as well.

For systematic analysis of qualitative data, the eight steps by Tesch (outlined in Creswell, 1994:155) were followed to encode data and categorise themes. Data verification was conducted through Guba's (in Krefting, 1991:215-222) model of trustworthiness of qualitative research. To enhance the quality of the research, especially credibility, the researcher applied 
triangulation of data sources by gathering qualitative data from students, the principal lecturer and markers of the research module. In addition, triangulation of data methods and data sources was employed by using various means to obtain information such as guides with open-ended questions, telephonic discussions and face-to-face semi-structured interviews (Guba's model outlined in Krefting, 1991:219). The research findings are presented in the next section.

\section{RESEARCH FINDINGS}

The research findings are presented by stating the themes and sub-themes followed by quotations to support the emerging theme.

Theme 1: Number of modules students register for at fourth-year level

The number of modules that students are permitted to register for at fourth-year level in an ODL setting is a contentious issue, since it has a bearing on the students' performance and completion of their research projects. At UNISA fourth-year student social workers are permitted to register for a maximum of ten modules (with an equivalent number of credits), if they meet a set of criteria. Even though clear conditions are spelled out in the University Calendar (2010a:139) on the number of modules for which a student may register, the responsibility lies with students to realistically decide on the workload that they would be able to cope with given their other responsibilities such as family and employment.

The responses of four students below encapsulate the views of all the participants (students). On average, the participants had registered for five modules. The least number of modules registered for was four and the highest ten. Some of the participants were able to make arrangements with their employers to have time to focus on their studies as illustrated in the following excerpts:

I had registered 4 modules (3 Criminology Modules on $3^{\text {rd }}$ level and the Social Work Research Module SCK 410B) and was in full-time employment.

I had registered 5 social work modules and was in full-time employment when I started my studies in 2010 but changed it to part-time employment during the year. My hours were flexible.

I had registered 7 social work modules - was not employed but looking after my family and it was difficult to manage time. Had to wake up in the early hours or stay late at night to study.

I had registered 10 social work modules and experienced the workload as demanding, although I tried not to let it affect my research study. I applied for sabbatical leave from my employer (I am permanently employed) and was given sabbatical leave from February to October 2010.

The views of the principal lecturer/coordinator ${ }^{5}$ and markers concerning the maximum number of modules (ten) for which students are allowed to register (in the ODL context) in relation to the successful completion of their research project generated a lot of responses.

The principal lecturer and all the markers suggested that fourth-year students should be allowed to register for a maximum of five modules. It can, therefore, be assumed that if the maximum number of modules to be registered at fourth-year level is set at five, this would alleviate

\footnotetext{
${ }^{5}$ The coordinator of this module is also the principal lecturer and his responsibilities include administration and coordination of all activities related to this module.
} 
pressure on students and many would be able to complete their research projects and this would lead to an increased throughput in the Department of Social Work. However, such a decision has serious implications for students, considering that they will not be able to complete the fourth level in one year but will need two years. At the moment the onus lies on the students to decide on the number of modules they would like to register for, especially those who performed exceptionally well in the previous year.

The markers were also of the view that students are allowed to register for too many (ten) modules at fourth-year level. However, they also acknowledged the fact that the circumstances of students differ. They support the view that students who study on a full-time basis and performing well should be permitted to register more than five modules at fourth-year level.

The markers offered practical suggestions on how to divide the fourth-year work load into two. Clearly such a suggestion requires further investigation and perhaps a survey should be undertaken among recent graduates to determine their perspective on this matter. The sentiments of the markers are illustrated by the following excerpt:

I think 5 modules maximum per year at $4^{\text {th }}$ level should be allowed. The ideal would be to do all the Management (SCK407/408), Research (SCK410B), and Statutory Work (SCK411) in the $1^{\text {st }}$ year and the remainder of the modules in their $2^{\text {nd }}$ year. Should they not complete the research in the $1^{\text {st }}$ year they can then continue with it in the $2^{\text {nd }}$ year.

The principal lecturer provided a comprehensive comment as follows:

Taking into consideration that most of our students come from disadvantaged backgrounds and were part of an educational system characterised by instability, coupled with the fact that many of them have employment and family responsibilities, makes it an unrealistic expectation to complete the $4^{\text {th }}$ level in one year. In order for the students to successfully complete their research project, the majority must spread the fourth-level modules over a period of two years, and the ideal would be that they start with the research module in the $1^{\text {st }}$ year of the $4^{\text {th }}$ level. The $4^{\text {th }}$ level in its current format is too loaded for students to complete in one year and only those who have the luxury of being a full-time student can complete it in one year.

Theme 2: The purpose of research in the social work curriculum

The responses provided by students underscored the importance of logical and critical thinking, including the furthering of social work knowledge. However, they omitted the significance of research in influencing policy and the fact that research knowledge will enable them to evaluate existing studies. The following comments represent the students' perspectives and understanding:

Having adequate knowledge of the research process enables social workers to embark on their own research studies in fields where they see social problems. Furthering the knowledge base of social work and its related topics also forms part of the code of ethics of social work.

To my knowledge, it serves to ensure that social workers are able to explore a specific situation and make recommendations based on their knowledge and experience. It helps a person to work systematically and logically through a situation and think critically. The research methodology assists in establishing a standard to report on certain occurrences/observations. 
The markers' responses were based on the students' acquisition of skills in reading, analysing, evaluating and writing a research report and to develop a sense of pride. The following comments sum up their responses:

It gives them the opportunity to think logically and present their logical thinking in a written format. It gives them the opportunity to practise their writing and reading skills properly. They get an opportunity to prepare a document neatly in a correct format from the title page to the bibliography and addendums. This is something they can really be proud of after they finish their studies - I still have both my honours and master's degree dissertations.

In general terms, the purpose of research in the social work curriculum is to enable students to develop capability to - think, argue and plan analytically as is required for all successful professional practitioners; undertake social work research in their day to day practice as social workers working in the field in order to improve their service rendering; and critically scrutinise, analyse and evaluate new developments in the social work profession as manifested in contributions to its body of knowledge, as part of their continued professional development.

The principal lecturer stated that:

One of the secondary methods of social work is social work research and it aims to sensitize students about research and its purpose in social work practice (i.e. to inform practice, interventions and policies) the research module SCK410B provides more theoretical knowledge (especially on qualitative research to complement the information obtained in the Module RSC $201^{6}$ about this approach and to put it into practice.

Unlike the principal lecturer, who offered the most appropriate explanation of the purpose of research in the social work curriculum, the markers only incorporated the link between research and practice in their explanation, but omitted the fact that research informs policy, as pointed out by Lewis (2003:579) that the primary purpose of social work research is to inform policy and practice, including shaping the body of knowledge and theory which informs practice.

Research is also viewed as a means of furthering social workers' understanding of the context in which they work, and a means of fostering the development of the professional body of knowledge for social work and the provision of best service to clients (Cameron \& Este, 2008:404). Conversely, Lundahl's (2008:274) assertion on the research methodology courses is that they "are designed to enhance students' ability to evaluate existing research to guide decisions, to investigate the efficacy of social work activities, and to build knowledge related to human condition".

Sub-theme: Students' attitudes towards research

The students' attitude of fear and ambivalence towards qualitative research projects is encapsulated in the following quotations:

I was initially scared by the concept "research", based on interactions with others who have conducted research. I was also fearful of not being able to meet the deadlines.

I was afraid of research given the hype around this research module. We were told by previous students that it is difficult and it has too much work.

\footnotetext{
${ }^{6}$ RSC 201 - Research in the Social Sciences Module offered at second-year level.
} 
These experiences confirm Strydom's (2008:384) finding that fourth-year students often convey negative perceptions about research to the other year groups and, by the time they reach fourth year, they are already negatively predisposed towards research.

However, some students indicated that the workshops helped them to deal with their fears as indicated in these excerpts:

After the workshop, I was no longer fearful of research because of the information provided.

I developed a positive attitude towards research after becoming part of Prof. Alpaslan's research team. The support I received made me feel at ease and confident.

Theme 3: The principal lecturer and markers views on students' perceptions of research, their attitude towards it and its relevance in social work practice

The presentation of this theme is divided into three sub-themes, which are presented below.

Sub-theme: Students' perceptions of research

The markers articulated their views on how students' perceive research as follows:

Students are confused and do not know where to start.

At the start of the research module (SCK 410B) most students had a vague idea of what research entails.

Most students are really scared of this module and do not expect to pass it the first time they enrol for it.

These findings confirm Adam, Zosky and Unrau's (2004:2) perceptions that research is "the curricular content that evokes the greatest amount of anxiety and the least sense of confidence among social work students". In addition, some authors (compare Gibbs \& Stirling, 2010:443; O'Connor \& O'Neill, 2004:27) are also of the view that social work students have genuine fears, anxiety and reluctance about social work research which need to be addressed to enable them to develop positive beliefs about social work research.

The principal lecturer raised critical factors that may impede the students' ability to implement research, such as the students' lack of knowledge about research and the amount of work entailed to complete the module, which is compounded by their lack of writing skills. Of great concern, though, is the observation that the work that students completed from levels 1-3 did not prepare them adequately for the demands of the research module. He articulated his concerns as follows:

Most of the students seem to underestimate the volume of work the research entails and the time it will consume. I think that the calibre of assignments they do from levels 1-3 do not serve to aid in preparing them for the research they have to do at $4^{\text {th }}$ level. I think they do too little written and comprehensive assignments in levels 1-3 and when they come to research they tend to treat it as a "small assignment" or a process report.

The principal lecturer's concern was confirmed and underscored by one of the markers who stated that:

The content of the revised edition (Study Guide RSC 201), should give students basic knowledge and understanding of research methodology. However, due to large student 
numbers, the assignments and examination are limited to multiple-choice questions that limit their understanding of the module.

Sub-theme: Students' attitude towards research

The markers made the following comments:

Students tend to see the research module as but one of the stepping stones leading to their qualification. It remains a challenge to enlighten them in this regard and to guide them in applying the research process and delivering the end product of a research report.

I believe that most students do not understand the relevance of the module. They just enrol for this because they have no other choice.

Students' attitudes towards research vary from positive to negative.

The principal lecturer stated that:

Because of being educated and informed via the grapevine about what research is all about (i.e. what it entails, and the amount of work involved) the students start out feeling negative, but once they engage themselves they start to become motivated and try their best.

This assertion has been confirmed by one of the student's quotations indicated above. Overall, these findings support the view that often students are unable to make the connection between research and practice (Cameron \& Este, 2008:391). Furthermore, with respect to research education courses generally, a significant number of students enter research classes with a negative attitude towards research (Berger cited in Cameron \& Este, 2008:391). Nevertheless, Amnon (1991:39) warns that 'in devaluating students' attitudes toward research, faculty in the academic setting and practitioners who supervise students in the field also may have developed correspondingly low expectations concerning the readiness of students to accept research content in their socialization to the profession".

Sub-theme: The students' views on the relevance of research in social work practice

The markers discovered that it is not easy for students to understand the link between research and practice, as evinced by the following quotations:

It is quite a challenge to enable students to see beyond their research project and for them to understand that they will have to be involved in some form of social work research as part of their day to day activities as practising social workers.

They see it as an isolated module.

Some of the markers held the view that, once students engage in data gathering, their level of understanding of the theory and practice is amplified and their enthusiasm increases as demonstrated in this excerpt: Many students enjoyed the process once they start with it and many were surprised at how well they performed eventually. This view is supported by Amnon's (1991:36) assertion that social work educators may be under-estimating the extent of the students' interest in research.

The following quotation by the principal lecturer indicates the gap that exists between the foundation Module - RSC 201 offered at second level and SCK-410B offered at fourth-year level. 
I might be generalising, but the majority of the students do no grasp the relevance of social work research for social work practice, as this is not clearly articulated in the foundation module. They view this module as one of the hurdles to be passed.

Theme 4: The principal lecturer and markers' overall assessment of the research reports One of the markers did not respond to this question as she was not involved in the final assessment of the students' research reports. However, the responses highlighted feelings of ambivalence and frustration, as illustrated by the following comments:

Due to the large number of students and the time factor involved, the overall assessment of the students' final research reports remain a challenge for the lecturer.

It is time consuming and challenging, especially if students ignored the comments on their drafts (Assignment 2).

On the other hand, the principal lecturer provided a more direct response indicating that diligent students who took cognisance of suggestions made by the markers completed their research projects successfully.

In the final assessment one can see which students attended the workshop and incorporated the feedback provided to them, as their reports are a cut above the rest.

Sub-theme: Students concerns regarding data collection and research report writing

The students' responses indicated that many were overwhelmed by how they should approach potential participants and handle disappointment as a result of people's reluctance to participate in their research studies. On the other hand, others were concerned about their lack of interviewing skills which they required to conduct face-to-face semi-structured interviews with the participants. Most of their reasons are encapsulated in the following responses:

Finding participants willing to be part of the research and being able to successfully gather the information necessary for the successful completion of the research project was a huge challenge.

First, I was concerned as to how I was going to obtain participants for my study as I did not want to impose on people. ... Second, I felt insecure about my ability to conduct interviews with my participants. Third, I was scared that I would misinterpret the data I had collected. Fourth, when I had to write the report I struggled to get a starting point and had to rewrite my report several times until it made sense.

The findings confirm the views expressed by the research supervisors in the study conducted by Todd et al. (2006:168) regarding the fact that students experience problems in the writing of a research report, particularly around structure and coherence.

Theme 5: The value of the research workshops

The main advantage of the research workshops for students appeared to have been clarification of the information provided in the study guide. However, some students needed assistance with the process of conducting face-to-face semi-structured interviews. For instance, one of the students indicated that:

During the workshop, no time was given as to how to conduct the research interview. It would have been helpful to do some role plays. 
This shortcoming was also highlighted by one of the markers, who indicated that students should be provided with assistance and/or support when they conduct face-to-face semistructured interviews with potential participants for their studies. She stated:

All I am really missing is the fact that students don't get more guidance during the process of interviewing their participants and the writing of Chapters 2 and 3. I, however understand that, due to ODL, this is difficult and think that students are performing exceptionally well with the guidance they do receive.

Sub-theme: Markers' perspectives on the research workshops

The principal lecturer was commended on by all markers for the good work. One stated: The present lecturer is going out of his way to assist students. She then proceeded to make the following suggestions for the improvement of the workshops:

I, however, think that the workshops are too large for students to benefit. If they could be smaller so that students could be divided into smaller groups, assisted by more lecturers, during the workshops they should benefit even more.

The discrepancies in the amount of time devoted to the other social work modules may mislead students into thinking that some modules are more important than others. One of the markers made reference to the imbalance between the amount of time allocated for the research workshops compared with other social work modules with an equivalent number of credits. She stated that:

I think that workshops should not be twice a year for only half a day. If you compare the time spent on e.g. modules SCK 402, SCK 403/4 and SCK 406 versus SCK 410, it is clear that there is a huge disparity, especially as all the fourth-level modules carry the same weight.

It is hoped that suggestions provided by the principal lecturer (in the section below) will alleviate this disparity.

Theme 6: The views of students on the markers' feedback

The responses from the students who stated that the feedback they received from the markers on Assignment 2 were adequate are encapsulated in the following quotation:

The comments made enabled me to see direction and I was able to include them in my final research report I guess that is why I made it.

However, another indicated that the comments on her Assignment 2 were not substantive on the content related to the field of study. She stated that:

The feedback I was provided on my draft research report was inadequate in terms of content-feedback focused on research methodology and lacked direction in terms of the study itself.

This finding is contrary to the expectations of the Department of Social Work of markers and students. In the ODL context educators are expected to guide students using various means of communication. However, markers who are not confident about their ability to provide feedback to students should seek assistance. Conversely, students are expected to take responsibility for their own learning by taking the initiative to request clarification and feedback (Roblyer \& Ekhaml, 2000:8).

However, a comment by one of the markers about the feedback provided to students underscores the importance of a proper assessment and extensive feedback to students on their 
draft research reports (Assignment 2), since these reports are a precursor to the final report. The marker stated:

I think that the assessment of the draft report is much more important in terms of feedback, as this is the students' guideline for the final report.

In the ODL context it is imperative that students should be proactive and follow up with the respective supervisor. The challenge for markers, though, is to keep abreast of developments in the various fields of social work in which students are doing research. This may pose a challenge in a situation where markers are expected to guide students who are doing research in, for example, more than three different fields of social work.

\section{SUGGESTIONS FOR THE DEPARTMENT SOCIAL WORK}

Students offered a range of practical suggestions that would assist the Department of Social Work in the ODL context to transform the preparatory process for fourth-year students and to enhance their performance in the research module (SCK 410B). Their views are summed up in the excerpts presented in Table 3 below.

\section{TABLE 3 \\ SUGGESTIONS OFFERED BY STUDENTS}

\begin{tabular}{|c|c|}
\hline Aspects & Statements made by the participants \\
\hline $\begin{array}{l}\text { Research } \\
\text { literature }\end{array}$ & $\begin{array}{l}\text { Students indicated the following challenges regarding information on research: } \\
\text { Research literature is ambiguous and often contradicts each other. } \\
\text { I struggled with the theory since the text books differed on important topics and } \\
\text { found the definitions ambiguous. } \\
\text { These findings confirm an observation by O'Connor and O'Neill (2004:24) that } \\
\text { lack of understanding of the qualitative paradigms can lead one to find it difficult } \\
\text { to make sense of the contradictory directives found in the qualitative research } \\
\text { literature regarding the research process and decision making. }\end{array}$ \\
\hline $\begin{array}{l}\text { Prescribe } \\
\text { research text } \\
\text { book }\end{array}$ & $\begin{array}{l}\text { There was a general outcry among the participants for the module to have a } \\
\text { research prescribed book that would assist students to comprehend research } \\
\text { concepts and the process. } \\
\text { I would suggest that UNISA prescribes one research methodology textbook in } \\
\text { order for students to have a clear understanding of what is required practically. } \\
\text { A prescribed or recommended book would alleviate some of the confusion } \\
\text { experienced. }\end{array}$ \\
\hline $\begin{array}{l}\text { Allocation o } \\
\text { to specific ta }\end{array}$ & $\begin{array}{l}\text { It could benefit students if an example of how to break down time for the different } \\
\text { stages of the research process was presented. }\end{array}$ \\
\hline $\begin{array}{l}\text { Improvement of } \\
\text { students' } \\
\text { interviewing } \\
\text { skills }\end{array}$ & $\begin{array}{l}\text { Although qualitative research and semi-structured interviews are by nature flexible, } \\
\text { clearer guidelines should be given on how to conduct a research interview. It may also } \\
\text { be helpful if this first attempt at conducting research was of a more structured nature. } \\
\text { The inclusion of role plays during the research lectures/workshops could benefit } \\
\text { students. }\end{array}$ \\
\hline $\begin{array}{l}\text { Dissemination of } \\
\text { information to } \\
\text { students on time }\end{array}$ & $\begin{array}{l}\text { Give students information early in the year to allow them to plan better. Inform } \\
\text { students on the items necessary for the research and the cost of the research (e.g. } \\
\text { tape recorder, typing and printing of transcripts/research report). Make sure that } \\
\text { study materials are timeously received by students. }\end{array}$ \\
\hline $\begin{array}{l}\text { Time scl } \\
\text { for work }\end{array}$ & $\begin{array}{l}\text { Start the year early for students. The research workshop should be conducted early } \\
\text { in the year to enable the students to start early. }\end{array}$ \\
\hline
\end{tabular}


Suggestions by the markers focused on ways to help students build a solid foundation at lower levels which would culminate in the integration of theory and practice through a research project at fourth-year level. They stated the following:

It might be meaningful to have a second-year module focusing on social work research. Knowledge should, however, "be kept alive" in the third year as well.

Develop a research module specific for Social Work at third-year level with workshops and written assignments.

Suggestions offered by the principal lecturer were comprehensive and encouraging. They provided answers to some of the concerns raised by students and markers related to the number of research seminars, the schedule for them, and management of large groups of students at workshops.

When critically appraising the support provided to students, I am of the view that if students can get a $3^{\text {rd }}$ workshop to aid them when they are conducting (the) field work, they would perform better in this activity. The first workshop should be earlier in the year. Currently it is presented in the regions from end of February to middle March. In some regions (i.e. Pretoria, Johannesburg and Durban) the numbers of students attending these workshops are too large and not all the students benefit optimally from this learning experience. For 2011 it is envisaged that more facilitators will be involved and the students will be divided into smaller groups in the venues mentioned. It is also envisaged that a $2^{\text {nd }}$ face-to-face workshop will also be conducted in Durban and Polokwane and not a video conference.

Suggestions from the student participants to prospective students

The 2010 students offered important, achievable and realistic suggestions to future students enrolling for the Module SCK 410B, which include: diligence by students in the completion of assignments, working in collaboration with other students, setting targets and time management. They stated the following:

Ensure that the grid (Assignment 1 - research plan) is done as comprehensively as possible - by the time students do the grid, they should have already done a literature study and become familiar with the topic they have chosen.

Become part of a research group because the support is invaluable.

Establish relationships with other students to minimise the feeling that you are "doing it alone". Share resource materials and ideas with other students. Do not be afraid to approach lecturers as I have always been helped when I have asked for support.

Time management is of utmost importance. In order to deal with feeling overwhelmed students should set small achievable targets. For example, do not attempt to write the research report in one sitting, do one section at a time and allow enough time to edit.

\section{CONCLUSION AND RECOMMENDATIONS}

Overall, the aim of the study, which was to explore the perceptions of (i) students who passed the research module in 2010; (ii) the principal lecturer and markers on factors that hinder students' execution and completion of their research projects, was achieved. The study afforded students an opportunity to reflect on their research experiences and accomplishments. The principal lecturer and markers also reflected on their roles and experiences in marking the 
students' research projects. Both groups offered viable suggestions to the Department of Social Work.

In a residential university it may be easy for educators to observe and help students who are overwhelmed, anxious and fearful of meeting the requirements of the module. Such an emotional state has far-reaching negative implications for the student-supervisor relationship, unless it is detected early and addressed properly. In an ODL context, however, it is imperative for markers to recognise confusion in the assignments of the students and suggest ideas on how to mitigate such a situation. Failure to do so may result in the students' despondency and/or discontinuation of the research module. It should be borne in mind that the challenge for the social work research educators remains the production of what Gibbs and Stirling (2010:448) refer to as "more competent research-minded social workers".

The guide with open-ended questions proved useful for the participants, as they were able to write their impressions in their own words. Several areas of concern were raised that would require the department's prompt attention such as: the students' lack of writing skills, review of the foundation research module (RSC 201) offered at second-year level (assess to what extent it caters for social work students); a prescribed research manual; review the number of seminars to be conducted per year and their duration.

Even though the principal lecturer anticipates an increase in the number of markers (given the increasing number of students), it is essential for the following suggestions to be taken into account: Ensure that a team of markers is competent and should:

- reach a consensus on the research content to be taught to students and the mode of instruction to ensure uniformity;

- know their roles and responsibilities;

- be trained and afforded an opportunity to conduct seminars with a reasonable number of students to allow time for simulation such as role playing how to conduct face-to-face semistructured interviews with the research participants;

- collaborate in designing an instrument that would be used to evaluate the facilitators of the research seminars;

- mark assignments of students who are doing research in at least two (maximum three) fields of social work. Such an arrangement will enable markers to keep abreast of developments in those fields (considering that they are employed on a part-time basis) and thus be able to provide effective feedback to students;

- hold discussions at the end of the year to assess and evaluate the general performance of students. Identify challenges and propose a plan of action;

- be delegated certain responsibilities currently carried out by the principal lecturer to enable him to devote time to monitoring and evaluating the performance of students and the competence of markers, and to pursue new initiatives for the improvement of research instruction.

The new incumbents in the ODL setting with or without previous knowledge and experience in supervision of research projects should familiarise themselves with the mode of facilitation of research seminars, particularly the support and effective feedback required by fourth-year students to enhance their performance in carrying out research projects. 


\section{RECOMMENDATIONS FOR FUTURE RESEARCH}

Some of the areas that require further exploration:

- A national in-depth study on the factors that impede students' planning, execution and implementation of their research projects in an ODL context. The study should include students from rural areas;

- A study to determine how students from diverse backgrounds learn research. Such information will benefit educators when they design research module(s);

- Establish the level of satisfaction of social work students with research education at UNISA;

- Conduct a survey to establish the reasons that lead to students' deregistration from Module SCK 410B (Social Work Research);

- Conduct research to compare on-campus and off-campus research education to determine the benefits for each group of students and their performance levels. The findings will benefit both contexts and will also inform decisions on the transformation of research education in social work;

- Conduct a national survey to determine the needs of social workers in research education including their enthusiasm and readiness to enrol for short courses in research methodology. Such courses should underscore the importance of evidence-based practice (EBP). If a pool of empowered, knowledgeable and skilled social workers is created, this would serve as a fertile ground for universities to consider encouraging students to embark on research projects that are carried out in conjunction with their practicum placements. In this way, they will be responding to the needs of the social service organisations and communities simultaneously. Contact with past students should be maintained as they may be instrumental in assisting with this endeavour. In addition, such an effort will also promote continuous learning and development among newly qualified social workers.

\section{REFERENCES}

ADAM, N., ZOSKY, D.L. \& UNRAU, Y.A. 2004. Improving the research climate in social work curricula: clarifying learning expectations across BSW and MSW research courses. Journal of Teaching in Social Work, 24(3/4):1-18.

ALPASLAN, A.H. 2010. Social work research: a step-by-step guide on how to conduct your fourth-year research project and write the research report. Study guide for SCK410B. Pretoria: University of South Africa.

AMNON, L. 1991. Faculty, practitioner, and student attitudes towards research. Journal of Social Work Education, 27(1):34-40.

BLAKELY, T.J. 1992. A model for distance education delivery. Journal of Social Work Education, 28:214-221.

BLESS, C. \& HIGSON-SMITH, C. 2000. Fundamentals of social research methods: an African perspective. Cape Town: Juta.

BOURN, D. \& BOOTLE, K. 2005. Evaluation of a distance learning, post graduate advanced award in social work programme for child and family social work supervisors and mentors. Social Work Education, 24(3):343-362. 
CAMERON, P.J. \& ESTE, D.C. 2008. Engaging students in social work research education. Social Work Education, 27(4):390-406.

CRESWELL, J.W. 1994. Research design: qualitative and quantitative approaches. Thousand Oaks, Calif: Sage Publications.

CRESWELL, J.W. 2009. Research design: qualitative, quantitative and mixed method approaches $\left(3^{\text {rd }}\right.$ ed). Thousand Oaks, Calif: Sage Publications.

DELPORT, C.S.L. \& FOUCHÉ, C.B. 2005. The place of theory and literature review in the qualitative approach to research. In: DE VOS, A.S., STRYDOM, H., FOUCHÉ, C.B. \& DELPORT, C.S.L. Research at grassroots - for the social sciences and human service professions $\left(3^{\text {rd }}\right.$ ed). Pretoria: Van Schaik Publishers.

DEPARTMENT OF SOCIAL WORK, UNISA. 2008. Strategic Project Submission. Pretoria: University of South Africa.

DUNLAP, K.M. 1993. A history of research in social work education: 1915-1991. Journal of Social Work Education, 29(3):293-301.

FOSSEY, E., HARVEY, C., McDERMOTT, F. \& DAVIDSON, L. 2002. Understanding and evaluating research. Australian and New Zealand Journal of Psychiatry, 36:717-732.

GIBBS, A. \& STIRLING, B. 2010. Reflections on designing and teaching a social work research course for distance and on-campus students. Social Work Education, 29(4):441-449.

HARDCASTLE, D.A. \& BISMAN, C.D. 2003. Innovations in teaching social work research. Social Work Education, 22(1):31-43.

KREFTING, L. 1991. Rigor in qualitative research: the assessment of trustworthiness. The American Journal of Occupational Therapy, 45(3):215-222.

LEWIS, R. 1995. The creation of an open learning environment in HE, innovation and learning in education. The International Journal for the Reflective Practitioner, 1(2):32-36.

LEWIS, C. 2003. Preparing the next generation of researchers. Social Work Education, 22(1/2):213-225.

LUNDAHL, B.W. 2008. Teaching research methodology through active learning. Journal of Teaching in Social Work, 28(1/2):273-288.

MNGUNI, S.J. 2010. Discussion held on 14 December with a policy developer in the Service Standards Directorate of the National Department of Social Development. Pretoria.

MONETTE, D.R., SULLIVAN, T.J. \& DEJONG, C.R. 2008. Applied social research: a tool for the human services $\left(8^{\text {th }}\right.$ ed). London: Thompson Brooks/Cole.

NEUMAN, W.L. 2006. Social research methods: qualitative and quantitative approaches. New York: Allyn and Bacon.

O’CONNOR, D.L. \& O’NEILL, B.J. 2004. Toward social justice: teaching qualitative research. Journal of Teaching Social Work, 24(3/4):19-33.

ROBLYER, M.D. \& EKHAML, L. 2000. How interactive are your distance courses? A rubric for assessing interaction in distance learning. [Online] Available: http://www.westga.edu/ distance/roblyer32.html. 
SCHENK, C.J. 2009. The socio-economic realities of the Social Work students of the University of South Africa. Social Work/Maatskaplike Werk, 45(3):299-313.

SCHENK, R. \& GROBLER, H. 2009. Person-centred facilitation: process, theory and practice $\left(3^{\text {rd }}\right.$ ed). Cape Town: Oxford University Press.

SIEGAL, E., JENNINGS, J.G., CONKLIN, J. \& NAPOLETANO-FLYNN, S. 1998. Distance learning in social work education: results and implications of a national survey. Journal of Social Work Education, 34(1):71-80.

STRYDOM, H. 1998. 'n Profiel van maatskaplike werkers en opleiding in navorsing. [A profile of social workers and training in research.] The Social Work PractitionerResearcher/Die Maatskaplikewerk-Navorser-Praktisyn, 11(1):53-68.

STRYDOM, H. 2008. The social work research module(s) from a social welfare perspective. Social Work/Maatskaplike Werk, 44(4):381-395.

TODD, M.J., SMITH, K. \& BANNISTER, P. 2006. Supervising a social science undergraduate dissertation: staff experiences and perceptions. Teaching in Higher Education, 11(2):161-173.

TUTTY, I.M., ROTHERY, M.A. \& GRINNELL, R.M. 1996. Qualitative research for social workers: phases, steps and tasks. Boston, Mass: Allyn \& Bacon.

UNISA - UNIVERSITY OF SOUTH AFRICA. 2005. Strategic Plan 2015. Pretoria: University of South Africa production services.

UNISA - UNIVERSITY OF SOUTH AFRICA. 2008. Open distance learning policy. Pretoria: University of South Africa.

UNISA - UNIVERSITY OF SOUTH AFRICA. 2010a. Calendar - Subjects and Syllabuses (Part 2). Pretoria: University of South Africa Production Services: 138-140.

UNISA - UNIVERSITY OF SOUTH AFRICA. 2010b. UNISA Examinations: Mark Composition Report for SCK 410B. Released on 02/12/2010.

UNISA - UNIVERSITY OF SOUTH AFRICA. 2010c. UNISA Internal Student System Statistics.

UNRAU, Y.A. \& GRINNELL, R.M. (Jr) 2005. The impact of social work research courses on research self-efficacy for social work students. Social Work Education, 24(6):639-651.

Prof Mankwane Makofane, Department of Social Work, University of South Africa, Pretoria, South Africa. 